\title{
Effect of Transactional Leadership on Students' Unrest in Public Boarding Schools in Bungoma County in Kenya
}

\author{
Moses Wakachala, Sarah Likoko, Jane Barasa \\ Department of Educational Planning and Management, Kibabii University, Kenya
}

\begin{abstract}
Incidences of student indiscipline in public learning institutions in Kenya have been rising sharply over the past decade culminating into many cases of school unrests. Consequently, loses of property and lives, insecurity and compromised quality of education have taken root in the schools raising questions as to whether Principals of the institutions undertake appropriate practices that can enhance order in leadership of public Secondary Schools under their jurisdiction. The study therefore sought to determine the influence of transactional leadership on student unrest. The study adopted a descriptive research design. The target population was 76 deputy principals, 152 teachers and 3,040 form four students in public boarding secondary schools. Multistage sampling was used in this study where schools were clustered into two categories. A simple random sampling technique was used to select 12 schools and 480 form four students from the categories. Purposive sampling was then used to select 12 deputy principals in charge of administration, 24 heads of boarding sections and teachers in charge of guidance and counselling departments in the schools. Questionnaires and interview schedules were used to collect data from the respondents. Reliability of the instruments was determined through test-retest method and a Cronbach Alpha coefficient of 0.734 was computed, which was considered sufficient for use of the questionnaires in the actual study. Research instruments were availed to supervisors who ascertained the relevance of items hence the validity of the instruments. Data was analysed using frequencies, means and the independent samples t-test statistics were conducted to compare differences between the two independent groups of schools. The study however did not establish a significant effects of transactional leadership style on student unrest.
\end{abstract}

Keywords: Boarding Schools, Transactional Leadership, Student Unrest

\section{INTRODUCTION}

A ccording to Bass (2000) transactional approach in management is based on the rewards and punishments. Rewards are given to those who achieves the target and punishment is given to those who fail to achieve the set targets. The leaders is keen on both psychological and physical behaviour through rewards and punishment. In a school situation rewards include material, financial and psychological gains. Punishment is administered through withdrawal of rewards.

Nguni, Sleegers \& Denessen (2015) explored the effects and transactional leadership effects on teachers' job satisfaction in primary school in Tanzania. They randomly sampled 700 teachers from 70 schools. The study used multiple regressions to establish the influence of transactional and transformational leadership styles on teacher job satisfaction and organizational commitment whereby the findings indicated that the leadership styles positively affected the outcome variables. Transactional leadership style was found to have no significant and weak aggregate effect on value commitment and organizational citizenship behaviour. In turn teacher job satisfaction is expected to impact positively on student achievement and behaviour. While the study focussed on teacher job satisfaction, it did not consider the effectiveness that may result due to organizational commitment in relation to student behaviour or achievement. The current study assessed transactional leadership focussing on its impact on student behaviour which may manifest through unrest.

Iyaya (2017) explored the relationship between principal leadership style and student discipline problems in secondary schools in Bungoma and Kakamega counties of Kenya where students, parents, teachers and DQASOs were sampled for the study. Responses from questionnaires and interview schedules were analysed using a correlation analysis. The study concluded that transactional leadership approaches increases discipline problems in secondary schools. The study focused on general discipline problems in schools under study, such problems may not be disruptive to the teaching and learning process and may have no cost implications. Hence this study dealt with student unrest which is more manifest in disruptive activity, arson and even loss of student lives which therefore has been of national concern.

In a relatively recent study, Njami and Bula (2018) evaluated the effect of principals' leadership styles on student discipline in public secondary schools in Nakuru County. Stratified sampling, simple random sampling, and purposive sampling techniques were used to select a sample of 119 respondents consisting of principals, teachers and students. The findings of the study indicated a significant relationship between principals' transformational style of leadership $(\mathrm{r}=0.868$, $\mathrm{p}<0.05)$, transactional style $(\mathrm{r}=0.602, \mathrm{p}<0.05)$, democratic style $(\mathrm{r}=0.782, \mathrm{p}<0.05)$, and autocratic style $(\mathrm{r}=-0.467$, $\mathrm{p}<0.05$ ) with students' discipline in public secondary schools in Nakuru County. A multiple linear regression model for the study had an R2 value of 0.731 and F-statistic of $F(4,105)=$ 
38.992, $\mathrm{p}<0.05$ was obtained implying principals leadership style could explain up to $73.1 \%$ of variations in discipline cases. The study concluded that among the other leadership styles used by principals in secondary schools included in the study, Transactional Leadership Style affected student discipline. The study used a descriptive research design which is limited in power to utilize inferential statistics in arriving at conclusions. The current study employed ex-post-facto comparing the influence of transactional leadership style in Entropy and Negentropy schools and as such the design validates use of the independent samples t-test, which helps to draw more reliable conclusions.

A study by Muga, Onyango \& Nyerere (2017) established that transactional leadership style was occasionally practiced alongside transformational leadership styles by principals in Siaya, Kisumu and Kajiado counties. Majority of the respondents included in their study $(69.3 \%)$ were of the opinion that principals occasionally used transactional leadership regardless of the discipline status of the schools. The mean response scores and standard deviation for each individual transactional leadership style sub-factors showed that contingent reward $(\mathrm{M}=2.91$. $\mathrm{SD}=0.751)$ was the highest perceived contributing factor of transactional leadership. While the study examined the use of transactional leadership style in three counties with use of descriptive statistics, the current study not only assessed the use of transactional leadership style by principals in Bungoma County, but also analysed the influence of the style on student unrest with use of the inferential statistics to establish differences.

\section{RESULTS AND DISCUSSION}

\subsection{The Influence of Principal's Transactional Leadership Style on unrest in public boarding secondary schools}

The objective of this study was to determine the influence of the principals' use of transactional leadership style on student unrest in public boarding secondary schools in Bungoma County, Kenya. The researcher sought to find out opinions of teachers and students differently from Group I schools (Negentropy schools) which are those that have never had unrest in the past 4 years and from group II (Entropy schools) which are schools that have had unrest in the past four years. A descriptive summary of their responses were therefore presented separately as below.

\subsection{Descriptive analysis for Negentropy public boarding secondary schools}

Questionnaires were administered to teachers and students in schools which had been reported to have had no cases of unrest in the last four years. They were required to rate their opinions on a five point likert scale against some statements on their principal's leadership practices which could enable the researcher establish the use of transactional style in the public boarding secondary schools which could likely account for absence of unrest. Their responses are presented in table 1 below.

Table 1: Negentropy (Group I) schools Responses on Transactional Leadership

\begin{tabular}{|c|c|c|c|c|c|c|c|c|}
\hline STATEMENT & SA & A & NS & D & SD & $\Sigma f i$ & $\Sigma f i w i$ & $\frac{\Sigma f i w i}{\Sigma f i}$ \\
\hline Punishment in this school fair & 60 & 55 & 11 & 84 & 31 & 241 & 752 & 3.12033 \\
\hline Well behaved students rewarded & 55 & 64 & 2 & 59 & 61 & 241 & 716 & 2.970954 \\
\hline $\begin{array}{c}\text { Students who misbehave denied privileges } \\
\text { Principal encourages students to follow school } \\
\text { rules and regulations }\end{array}$ & 57 & 65 & 72 & 2 & 56 & 42 & 241 & 793 \\
\hline Students happy with their school & 67 & 54 & 15 & 86 & 19 & 241 & 787 & 3.29046 \\
\hline
\end{tabular}

Source: Field data (2020)

When required to rate opinion on whether Punishment in this school is fair, there was a divided opinion among the respondents. There was a relatively divided opinion with $115(48 \%)$ disagreeing and $115(48 \%)$ agreeing with the statement while only $11(5 \%)$ indicated not being sure. With a weighted average of 3.12 it can be deduced that their opinions were similar but a slight tilt towards agreement with the statement. In the schools most respondents felt students are treated fairly over discipline issues which may account for absence of unrest since students are contented with discipline procedures.

When required to rate their opinion on whether well behaved students are always rewarded, a large majority of the students in the calm schools which was $120(50 \%)$ disagreed while $119(49.6 \%)$ agreed with the statement and 2(1\%). Hence the weighted average for the statement was 2.97 which indicated that most of the students in schools that have never experienced unrest in the past four years generally opined that well behaved students are never always rewarded. Use of rewards could hence not explain the existence of high levels of discipline and presence of low chances of unrest.

The respondents were asked whether Students who misbehave are denied privileges and majority of $122(51 \%)$ were in agreement, 105(51\%) disagreed while 14(6\%) were not sure giving a weighted average for the statement of 3.16 which in this case indicate that on average, schools that had been calm had alternative measures of containing indiscipline hence a low likelihood of unrest. 
Further the respondents were asked to indicate their opinion on whether Principal always encourages students to follow school rules and regulations. A total of 141(59\%) respondents agreed while $98(44 \%)$ disagreed and $2(1 \%)$ were unsure of the statement giving a weighted average of 3.29. This imply majority of the respondents in schools that had not had unrest indicated that principals in their schools always encouraged students to follow rules and regulations. This could account for the peaceful environment experienced in the schools.

With regard to whether Students are happy with their school, a larger number of $121(50 \%)$ were in agreement while $105(44 \%)$ disagreed with the statement and 15(6\%) indicated not sure. With a weighted average of 3.27 , it can be concluded that on average, students in schools which are calm are happy with their schools hence are less likely to engage in cases of unrest.

\subsection{Aggregation of ratings in Negentropy public boarding secondary schools for principals' transactional leadership style}

The ratings for each respondent on the various indicators of principals' transactional leadership in the Negentropy public boarding secondary schools were summed up to obtain an index which measured level of transactional leadership application. The index ranged from 5 to 25 where an index of 5 implied lowest rating on principal's transactional leadership style and an index of 25 imply highest rating. An average value of 15 and above was considered high favourable ratings for existence of transactional leadership style while values lower than 15 were considered to be low ratings hence minimum application of transactional leadership style. The descriptive statistics for transactional leadership indices in Negentropy secondary public boarding Secondary schools are presented in Table 2.

Table 2: Descriptive statistics for Transactional Leadership Indices for Negentropy public boarding secondary schools

\begin{tabular}{|c|c|c|c|c|c|c|}
\hline School Groups & N & Min. & $\begin{array}{c}\text { Max } \\
.\end{array}$ & Mean & $\begin{array}{c}\text { Std. } \\
\text { Dev. }\end{array}$ & $\begin{array}{c}\text { Std. Error } \\
\text { of Mean }\end{array}$ \\
\hline Negentropy & 241 & 6.00 & $\begin{array}{c}25.0 \\
0\end{array}$ & $\begin{array}{c}15.80 \\
91\end{array}$ & $\begin{array}{c}3.3336 \\
8\end{array}$ & .21474 \\
\hline
\end{tabular}

Source: SPSS output (2020)

The table 2 reveals a slightly high mean rating for the principals' transactional leadership style among the Negentropy public boarding secondary schools included in this $\operatorname{study}(\mathrm{m}=15.8091, \mathrm{sd}=3.33368)$. In schools that experienced unrest, principals demonstrated some levels of transactional leadership consciousness.

\subsection{Entropy public boarding secondary schools descriptive analysis}

The researcher administered questionnaires to teachers and students in schools which had been reported to have had a case of unrest in the last four years. They were required to rate their opinions on a five point likert scale against some statements on their principal's leadership practices which could enable the researcher establish the use of transactional style in the schools which could likely account for absence of unrest. Their responses are presented in table 3

Table 3: Entropy (Group II) school students' responses on transactional leadership styles

\begin{tabular}{|c|c|c|c|c|c|c|c|c|}
\hline STATEMENT & SA & A & NS & D & SD & $\Sigma f i$ & $\Sigma f$ iwi & $\frac{\Sigma f \text { iwi }}{\Sigma f i}$ \\
\hline Punishment in this school fair & 31 & 75 & 22 & 64 & 49 & 241 & 698 & 2.89627 \\
\hline Well behaved students rewarded & 24 & 80 & 22 & 86 & 29 & 241 & 707 & 2.93361 \\
\hline Students who misbehave denied privileges & 46 & 72 & 23 & 69 & 31 & 241 & 756 & 3.136929 \\
\hline $\begin{array}{c}\text { Principal encourages students to follow school rules } \\
\text { and regulations }\end{array}$ & 61 & 73 & 0 & 63 & 44 & 241 & 767 & 3.18257 \\
\hline Students happy with their school & 58 & 41 & 39 & 52 & 51 & 241 & 726 & 3.012448 \\
\hline
\end{tabular}

Source: Field data (2020)

When required to rate opinion on whether punishment in this school is fair, there was a divided opinion among the respondents. There was a relatively divided opinion with $113(47 \%)$ disagreeing and 106(44\%) agreeing with the statement while only $22(9 \%)$ indicated not being sure. With a weighted average of 2.896 it can be deduced that their opinions were similar but a slight tilt towards agreement with the statement. In the schools most respondents felt students are treated fairly over discipline issues.

When required to rate their opinion on whether well behaved students are always rewarded, a large majority of the participants in the calm schools which was $115(48 \%)$ disagreed while 104(43\%) agreed with the statement and $22(9 \%)$. Hence the weighted average for the statement was 2.93 which indicated that most of the participants in schools that have experienced unrest in the past four years generally opined that to some extent well behaved students could be rewarded.

The respondents were asked whether students who misbehave are denied privileges and majority of $118(49 \%)$ were in agreement, 100(41\%) disagreed while 23(10\%) were not sure giving a weighted average for the statement of 3.14 which in this case indicate that on average, schools that had unrest had 
alternative measures of containing indiscipline hence a low likelihood of unrest.

Further the respondents were asked to indicate their opinion on whether the principal always encourages students to follow school rules and regulations. A total of $134(56 \%)$ respondents agreed while $107(44 \%)$ disagreed with the statement giving a weighted average of 3.18. This imply majority of the respondents in schools that had not had unrest indicated that principals in their schools always encouraged students to follow rules and regulations.

With regard to whether Students are happy with their school, a larger number of 103(43\%) disagreed while 99(41\%) agreed with the statement and 39(16\%) indicated being not sure. With a weighted average of 3.01 , it can be concluded that there was divided opinion among respondents about the level of satisfaction of students with their schools.

\subsection{Aggregation of ratings in Entropy public boarding secondary schools for principals' transactional leadership style}

The ratings for each respondent on the various indicators of principals' transactional leadership in the Entropy public boarding secondary schools were summed up to obtain an index which measured level of transactional leadership application. The index ranged from 5 to 25 where an index of 5 implied lowest rating on principal's Transactional leadership style and an index of 25 imply highest rating. An average value of 15 and above was considered high favourable ratings for existence of transactional leadership style while values lower than 15 were considered to be low ratings hence minimum application of transactional leadership style. The descriptive statistics for transactional leadership indices in Entropy schools are presented in Table 4

Table 4. Descriptive statistics for Transactional Leadership Indices for Negentropy Schools

\begin{tabular}{|c|c|c|c|c|c|c|}
\hline $\begin{array}{c}\text { School } \\
\text { Groups }\end{array}$ & $\mathrm{N}$ & Min. & $\begin{array}{c}\text { Max } \\
.\end{array}$ & Mean & Std. Dev & $\begin{array}{c}\text { Std. Error } \\
\text { of Mean }\end{array}$ \\
\hline $\begin{array}{c}\text { Entrop } \\
\text { y }\end{array}$ & 241 & 9.00 & $\begin{array}{c}25.0 \\
0\end{array}$ & 15.1618 & 3.57695 & .23041 \\
\hline
\end{tabular}

Source: SPSS Output (2020)

Table 4 reveals a balance in the ratings of respondents in Entropy public boarding secondary schools as related to the principals with $m=15.1618, s d=3.57695$ which is indicates divided opinion among the application of the transactional style in the schools.

\subsection{Testing for differences in ratings for principal Transactional leadership style between Negentropy and Entropy public boarding secondary schools}

The study sought to establish the influence of principals' transactional leadership style on unrest, by determining the differences in the ratings between Negentropy and Entropy public boarding seconding schools by verifying the hypothesis states as below

$H_{0} 5$ : There is no statistically significant difference in the principals' use of transactional leadership style among Entropy and Negentropy public boarding secondary schools in Bungoma County

In order to verify the hypothesis, an independent sample t-test was conducted on the computed transactional leadership index for the Entropy and Negentropy public boarding secondary schools. The results of descriptive statistics of the test were presented in tables 5 .

Table 5: Descriptive statistics for Transactional Leadership Indices in Entropy Schools

\begin{tabular}{|c|c|c|c|c|c|}
\hline & $\begin{array}{c}\text { School } \\
\text { Groups }\end{array}$ & $\mathrm{N}$ & Mean & $\begin{array}{c}\text { Std. } \\
\text { Dev. }\end{array}$ & $\begin{array}{c}\text { Std. Error } \\
\text { Mean }\end{array}$ \\
\hline \multirow{2}{*}{$\begin{array}{c}\text { Transt } \\
\text { Index }\end{array}$} & $\begin{array}{c}\text { Negentr } \\
\text { opy }\end{array}$ & 241 & 15.8091 & 3.33368 & .21474 \\
\cline { 2 - 6 } & Entropy & 241 & 15.1618 & 3.57695 & .23041 \\
\hline
\end{tabular}

Source: Spss Output (2020)

The table 5 shows that ratings for both Negentropy and Entropy school was fairly balances and nearly the equal with Negentropy public boarding secondary schools recording a slightly higher ratings $(m=15.8091, s d=3.33368)$ while Entropy schools had lower ratings $(m=15.1618, s d=$ 3.57695). Hence it can be deduced that on average, there was minimal use of transactional leadership style by principals of both groups of schools.

The next part of the output consisted of the t-statistic, the degrees of freedom and the significance level which are presented in table 6

Table 6: Independent samples t-test for Aggregated Transactional Leadership Indices

\begin{tabular}{|c|c|c|c|c|c|c|c|c|c|}
\hline \multicolumn{3}{|c|}{ Levene's Test for Equality of Variances } & \multicolumn{7}{|c|}{ t-test for Equality of Means } \\
\hline & \multirow{2}{*}{$\mathrm{F}$} & \multirow{2}{*}{ Sig. } & \multirow{2}{*}{$\mathrm{T}$} & \multirow{2}{*}{ Df } & \multirow{2}{*}{$\begin{array}{l}\text { Sig. (2- } \\
\text { tailed) }\end{array}$} & \multirow{2}{*}{$\begin{array}{l}\text { Mean } \\
\text { Diff. }\end{array}$} & \multirow{2}{*}{$\begin{array}{l}\text { Std. } \\
\text { Error } \\
\text { Diff. }\end{array}$} & \multicolumn{2}{|c|}{$\begin{array}{c}95 \% \text { Confidence Interval } \\
\text { of the Difference }\end{array}$} \\
\hline & & & & & & & & Lower & Upper \\
\hline Equal variances assumed & 1.163 & .281 & 2.055 & 480 & .056 & .64730 & .31497 & .02842 & 1.26618 \\
\hline Equal variances not assumed & & & 2.055 & 477.638 & .056 & .64730 & .31497 & .02841 & 1.26619 \\
\hline
\end{tabular}

*ATI- Aggregated Transactional Leadership Index

Source: SPSS output (2020) 
An independent samples t-test comparing the mean of transactional leadership index in Entropy and Negentropy public boarding secondary schools was conducted. No significant difference was found between the means of the two groups of schools $(\boldsymbol{t}(\mathbf{4 8 0})=\mathbf{2 . 0 5 5}, \boldsymbol{p}>0.05)$. Hence the study failed to reject the null hypothesis $\mathbf{H}_{\mathbf{0}} \mathbf{5}$ stating that there is no statistically significant difference in the principals' use of transactional leadership style among Entropy and Negentropy public boarding secondary schools in Bungoma County. Implying that the principals in both groups of schools (Negentropy and Entropy Schools) were found to have marginally adopted Transactional leadership practices. From the findings, Student unrest in schools cannot be attributed to limited application of transactional leadership style by principals in the schools under study.

Muga et al. (2017) also established that transactional leadership style was practiced alongside transformational leadership styles by principals in Siaya, Kisumu and Kajiado counties regardless of the discipline status of the schools. However, few studies attempt to link transactional leadership to student discipline independently. This implies transactional leadership style may not be applied in isolation as a means to curb unrest.

The findings of this study are also supported by the study by Martin (2009) in a study carried out in five districts in the state of Georgia among 250 teachers which revealed that there was a positive relationship between contingent reward measured as a subscale of transactional leadership and school culture. The respondents in schools that were identified with a positive culture (Negentropy schools) rated fairly high on the likert scale $(\mathrm{M}=3.13, \mathrm{SD}=1.10)$ which demonstrated the link between the use of transactional leadership approach to positive attributes in a school environment such as low cases of indiscipline and hence low chances of student unrest.

A similar study by Njami \& Bula (2018) established a positive relationship between transactional leadership style and student discipline in Nakuru County. Using a sample of 119 respondents, the study determined a pearson's correlation coefficient $(r=0.602, \mathrm{p}<0.01)$ indicating that schools in which principals practiced transactional leadership styles generally had lower incidences of indiscipline. Katolo, Mungai, \& Malela (2016) also established that there was a significant relationship between principals' leadership practices and students' discipline. Using a Pearson Product-Moment Correlation, the study determined that there existed a negative correlation between principals' frequency of rewarding and the number of students' disciplinary cases $(r=-0.961, p<0.05)$. Hence the use of transactional leadership style has impact on student discipline and unrest.

Despite the fact that transactional leadership style was rated low in both the Negentropy $(m=16.3527, s d=4.25589)$ and Entropy schools ( $m=15.6971, s d=4.41063)$ included in this study, many other studies tend to advocate its use as an effective method of managing student discipline hence reducing chances of student unrest.

\subsection{Assessing the influence of intervening factors}

The current study had identified some factors which were anticipated to have some influence on the dependent variable, which is the unrest in public boarding secondary schools in Bungoma County apart from principals' leadership styles which were government policies on education matters such as delocalization of teachers, regulation of discipline methods used in schools and the involvement of the members of communities around schools.. In order to isolate their influence, the researcher sought the opinion of respondents to determine the extent of the influence of the intervening factors on school stability.

Respondents were required to rate their opinion on a five point likert scale to indicate their level of agreement against some statements that related to other factors to which the unrest could have been attributed to rather than the principals' leadership style. Their responses are presented in table 7.

Table 7: Group II Participants' Responses on Intervening Factors

\begin{tabular}{|c|c|c|c|c|c|c|c|c|}
\hline STATEMENT & SA & A & NS & D & SD & $\Sigma f i$ & $\Sigma f i w i$ & $\frac{\Sigma f i w i}{\Sigma f i}$ \\
\hline $\begin{array}{c}\text { Some people in the local community usually incite students to } \\
\text { cause unrest }\end{array}$ & 29 & 55 & 68 & 222 & 108 & 482 & 1121 & 2.33 \\
\hline $\begin{array}{c}\text { Some people in the local community sneak contraband goods to } \\
\text { students which can cause unrest }\end{array}$ & 24 & 24 & 84 & 152 & 198 & 482 & 970 & 2.01 \\
\hline $\begin{array}{c}\text { Punishment methods used by teachers in this school can cause } \\
\text { unrest }\end{array}$ & & 34 & 104 & 187 & 157 & 482 & 979 & 2.03 \\
\hline Transfer of principals could result into student unrest & 55 & 37 & 64 & 157 & 169 & 482 & 1098 & 2.28 \\
\hline The conduct of teachers can result into student unrest & 32 & 143 & 4 & 212 & 91 & 482 & 1259 & 2.61 \\
\hline \multicolumn{2}{|r|}{} & & & & $\bar{X}=\frac{\Sigma(\Sigma f i w i)}{\Sigma f i}$ & 2.25187 \\
\hline
\end{tabular}

Source: Field data (2020)

Table 7 shows that majority of the participants represented by $330(68 \%)$ disagreed that some people in the local community usually incite students while only 84(17\%) agreed and 68 $(15 \%)$ indicating not being sure about community incitement. 
Hence with a weighted average of 2.33 , it can be concluded that on average the responses indicate community around the school had minimally been involved in inciting respondents during the unrests.

When required to give response on some people in the local community sneak band goods to students which can cause unrest $350(73 \%)$ disagreed with the statement and only $48(10 \%)$ agreed and $84(17 \%)$ were not sure. The weighted average was low at 2.01 which indicate on average the respondents had opinion that community involvement in planning for the unrest was limited.

On whether punishment methods used by teachers in the school could cause unrest, majority of the participants represented by $344(71 \%)$ disagreed with the statement while only $34(7 \%)$ agreed and $104(22 \%)$ indicated being not sure. The value of the weighted average for the statement at 2.03 generally indicates the punishment methods used by teachers had little effect on student unrest.

The participants were further required to rate opinion on whether transfer of principals could result into student unrest. Again the majority, 326(68\%) disagreed while 92(19\%) agreed with the statement and 64(13\%) indicated being not sure. The weighted average of 2.28 for the statement indicates that generally the respondents had the opinion that the transfer of the principal was not the cause of the unrest that occurred.

The participants were further required to rate opinion on whether the conduct of teachers can result into student unrest. Again the majority, 302(63\%) disagreed while 175(36\%) agreed with the statement and $4(1 \%)$ indicated being not sure. The weighted average of 2.61 for the statement indicates that generally the respondents had the opinion that the conduct of teachers could not result into student unrest

In order to determine the influence of the intervening factors on unrest, the researcher computed the mean value of the weighted averages for the statements showing responses on the intervening factors. The computed mean, $\bar{X}=$ 2.25187 was low hence it imply the responses were generally in disagreement that external factors had much influence as causes of unrest. Hence the unrest can majorly be attributed to principal leadership style.

\section{CONCLUSION}

Based on the findings, the study concludes that the use of transactional leadership approaches by principals of public boarding secondary schools has limited effect on unrest.

\section{RECOMMENDATION}

In view of the study findings and the conclusions arrived at, the study recommended that Teacher training institutions must lay a stronger emphasis on institutional management curriculum in order to equip all teacher trainees with modern leadership management skills.

\section{REFERENCES}

[1] Iyaya, (2017). The Relationship between Principal Leadership Style and Student Discipline Problems in Secondary Schools. International journal of humanities and social studies 5 (7). Retrieved on 10/7/2020 at www.theijhss.com

[2] Katolo, G.N., Mungai, G.A., \& Malela, K.P. (2016). Principals' Leadership Practices and Their Influence on Students' Discipline in Public Secondary Schools in Makindu Sub County, Kenya. IOSR-JMCE. 13 (5). Retrieved on Sept 25, 2019 at https://www.iosrjournals.org

[3] Muga, O.P., Onyango A.G., \& Nyerere J. (2017). Leadership Styles Practiced by Principals in Public Secondary Schools in Siaya, Kisumu and Kajiado Counties, Kenya. European Journal of Education Studies 3 (9). Retrieved on 24th Nov, 2019 at https://www.10.5281/zenodo.846450

[4] Nguni, S., Sleegers, P. \& Denessen, E. (2015). Transformational and transactional leadership effects on teachers' job satisfaction, organizational commitment, and organizational citizenship behaviour in primary schools: The Tanzanian case. Tandfonline accessed on 19/7/2020 http://dx.doi.org/10.1080/09243450600565746 